\title{
PENGARUH KESADARAN PAJAK, SISTEM ADMINISTRASI PAJAK MODERN DAN SANKSI PAJAK TERHADAP KEPATUHAN WAJIB PAJAK PADA UMKM DI SURAKARTA \\ Zulaicha Efrita Sarasawati ${ }^{1}$ \\ Endang Masitoh ${ }^{1}$ \\ Riana Rachmawati Dewi ${ }^{1}$ \\ Fakultas Ekonomi Program Studi Akuntansi Universitas Islam Batik Surakarta ${ }^{1}$
}

\begin{abstract}
Abstrak
Goals the activities to provide business motivation as well as assistance commercialization of herbal drinks for the Regional Board Aisyiyah Malang. Aisyiyah management already has a cooperative that can be used as a container to market their products. During this product sold in the cooperative quite a lot, among others: school uniforms, school equipment, snacks and various types of beverages. However, the products sold, there is no production of Aisyiyah citizens themselves. Therefore, it is necessary to motivate the herbal beverage business for the board and members to capture the existing business opportunities, while providing commercialization assistance.The results of direct training is practiced and sold at every bazaar event that is always held every activity conducted by Economic and Entrepreneurship Assembly, PDA Malang. Advisory activities are carried out directly whenever any complaints or obstacles are encountered, such as issues related to storage durability or expiration period, hygienic packaging, unpleasant taste, use / addition of other materials, etc.
\end{abstract}

Keywords: Awareness Of Tax, The Tax Administration System Of Modern, Tax Compliance, Tax Sanctions

\section{PENDAHULUAN}

Pertumbuhan ekonomi Indonesia yang sedang melakukan perkembangan pembangunan maupun perbaikan di berbagai bidang, Indonesia membutuhkan sumber pendanaan dalam pelaksanaannya. Secara umum, sumber pendapatan suatu negara (Public Revenues) merupakan meliputi kekayaan alam, laba perusahaan negara (BUMN), royalti, retribusi, kontribusi, bea, cukai, dan yang terakhir pajak. Salah satu sumber pendapatan negara yaitu pajak, karena menjadi sumber utama dari pendapatan negara untuk membiayai seluruh pengeluaran negara. Banyaknya bentuk-bentuk usaha yang ada di Indonesia, baik dari usaha kecil, usaha menengah, maupun usaha besar merupakan salah satu bukti nyata perkembangan pembangunan dalam bidang ekonomi. Perekonomian Indonesia telah didominasi oleh kegiatan Usaha Mikro Kecil dan Menengah (UMKM).

Penerimaan pajak yang mencapai 81,54 persen dari target, penerimaan pajak secara keseluruhan per 31 Desember 2016 mencapai Rp 1.105 triliun, atau sebesar 81,54 persen dari target penerimaan pajak APBN. Perubahan 2016 yang sebesar Rp 1.355 triliun, target pendapatan negara dalam APBN tahun 2016 ditetapkan sebesar Rp 1.822,5 triliun atau Rp 25,6 triliun lebih rendah dari yang diusulkan dalam RAPBN Tahun Anggaran 2016. Target Pendapatan Negara tersebut bersumber dari Penerimaan Perpajakan sebesar Rp 1.546,7 triliun dan Penerimaan Negara Bukan Pajak sebesar Rp 273,8 triliun (rasio penerimaan negara terhadap PDB atau tax ratio dalam tahun 2016 sebesar 13,11 persen). Sehingga dapat dilihat pada realisasi penerimaan negara dari sektor pajak dominan APBN dari tahun 2007 sampai dengan RAPBN tahun 2016. Direktorat Jenderal Pajak (Dirjen Pajak) sebagai lembaga yang resmi di sektor pajak, yang kerja dan fungsinya dibawah naungan Departemen Keuangan yang mempunyai tugas untuk menampung dan mengemban penerimaan pajak dari seluruh rakyat atau seluruh warga negara (Setyabudi, 2017).

Rasio kepatuhan para UMKM dalam melaksanakan kewajiban perpajakannya supaya meningkat, maka diperlukan kesadaran masyarakat mengenai pentingnya pajak, baik dari segi pemungutan maupun manfaat, maka perlu diadakan edukasi mengenai pentingnya pajak serta dilakukan sosialisasi secara terusmenerus, baik melalui media cetak maupun media elektronik. Pentingnya pembayaran pajak untuk membiayai pengeluaran pemerintah dan pembangunan nasional maka wajib pajak tidak dirugikan karena dapat mendorong mewujudkan pertanggung jawabnya sebagai wajib pajak yang patuh. Kesadaran wajib pajak sangat sulit diwujudkan, sampai sekarang kesadaran masyarakat masih belum mencapai tingkat

\footnotetext{
${ }^{1}$ zulaichaefrita@gmail.com
} 
sebagaimana yang diharapkan. Wajib pajak yang patuh dan tidak melanggar norma dapat terhindar dari sanksi perpajakan. Sanksi perpajakan sebagai alat pencegah (preventif) menciptakan agar wajib pajak patuh dalam melaksanakan kewajiban perpajakannya, maka upaya peningkatan kepatuhan wajib pajak UMKM mutlak untuk dilakukan supaya terjaga stabilitas perekonomian di Indonesia. Maka dari itu kepatuhan pajak sangat berpengaruh pada perkembangan pembangunan ekonomi.

\section{Tujuan}

Tujuan yang hendak dicapai dalam penelitian ini adalah:

1. Untuk mengetahui kesadaran perpajakan terhadap pajak berpengaruh terhadap kepatuhan perpajakan.

2. Untuk mengetahui sistem administrasi pajak modern berpengaruh terhadap kepatuhan perpajakan.

3. Untuk mengetahui sanksi pajak berpengaruh terhadap kepatuhan perpajakan.

\section{METODE PENELITIAN}

Penelitian ini menggunakan metode kuantitatif. Metode kuantitatif adalah menekankan analisisnya pada data numerik (angka) yang diolah dengan metode statistik. Dengan menggunakan metode kuantitatif, maka akan diperoleh signifikansi terhadap perbedaan kelompok atau signifikansi hubungan antar variabel yang diteliti (Parjanti, 2014). Data yang digunakan dalam peneltian ini adalah data primer. Data primer merupakan sumber data yang didapat secara langsung melalui sumber asli (tidak melalui media perantara) dari hasil wawancara atau hasil pengisian kuesioner yang biasa dilakukan oleh peneliti. Data primer secara khusus dikumpulkan oleh peneliti yang kemudian diserahkan kepada responden untuk menjawab beberapa pertanyaan yang tercantum pada kuesioner (Indriantoro dan Supomo, 2009).

Populasi dalam penelitian ini adalah wajib pajak UMKM yang mematuhi pajak di Kota Surakarta, sedangkan sampel merupakan bagian dari populasi yang terdiri dari elemen-elemen yang diharapakan memiliki karakteristik yang mewakili populasinya (Sekaran, 2000). Sampel adalah sebagian jumlah karakteristik yang dimiliki oleh keseluruhan objek populasi (Soekidjo, 2005). Teknik pengambilan sampel pada penelitian ini menggunakan teknik pengambilan purposive sampling. Peneliti melakukan penelitian dengan menyebar 20 kuesioner dibagikan sejumlah 50 responden. Adapun kriteria sampel yang akan digunakan adalah sebagai berikut:

1. UMKM mempunyai NPWP

2. UMKM menjawab pertanyaan

Sumber data yang digunakan dalam penelitian ini adalah data primer. Responden dalam penelitian ini adalah wajib pajak di Kota Surakarta. Penelitian ini menggunakan metode pengumpulan data berupa metode observasi, dokumentasi, kuesioner, wawancara, dan studi pustaka. Kuesioner diukur dengan menggunakan skala likert yaitu memberikan penilaian atas jawaban responden dengan klasifikasi jawaban sangat setuju (SS) diberi skor 5, setuju (S) diberi skor 4, netral (N) diberi skor 3, tidak setuju (TS) diberi skor 2, sangat tidak setuju (STS) diberi skor 1 yang diuji dengan validitas dan reliabilitas. Uji asumsi klasik yang terdiri dari: uji normalitas, uji autokolerasi, uji heteroskedasitisitas, uji multikolinearitas dan analisis regresi linier berganda antara lain;

1. Model Regresi Berganda

Analisis regresi linier berganda adalah teknik melalui koefisien parameter untuk mengetahui besarnya variabel independen terhadap variabel dependen.

2. Uji Kelayakan Model

Uji Kelayakan Model (F) merupakan tahap awal untuk mengindentifikasi model regresi tersebut apakah layak atau tidak.

3. Uji Hipotesis (Uji t)

Uji statistik t digunakan untuk melihat pengaruh variabel independen terhadap variabel dependen secara parsial.

4. Uji Koefisien Determinasi $\left(\mathrm{R}^{2}\right)$ digunakan untuk mengukur sejauh mana kemampuan model menerangkan variasi variable dependen. 


\section{Hasil dan Pembahasan}

Berdasarkan metode purposive sampling, sehingga sampel yang diperoleh sebagai data yang diperoleh sebanyak 40 responden.

\section{Hasil Uji Asumsi Klasik}

Uji asumsi klasik terdiri atas uji normalitas, multikolinearitas, heteroskedastisitas, autokorelasi, Berikut gambar hasil uji normalitas:

\section{Tabel 1. Hasil Uji Normalitas}

Tabel 1. One-Sample Kolmogorov-Smirnov Test

\begin{tabular}{lll}
\hline & & $\begin{array}{l}\text { Unstand } \\
\text { ardized } \\
\text { Residual }\end{array}$ \\
\hline $\mathrm{N}$ & Mean & 40 \\
Normal Parameters &, 0000000 \\
& Std. & 1,743569 \\
& Deviatio & 27 \\
Most Extreme & $\mathrm{n}$ &, 134 \\
Differences & Absolute &, 134 \\
& Positive &,- 102 \\
Test Statistic & Negative &, 134 \\
Asymp. Sig. (2-tailed) & &, $067^{\mathrm{c}}$ \\
\hline
\end{tabular}

Sumber: Data yang diolah

Berdasarkan gambar diatas uji normalitas residu dilakukan dengan menggunakan uji non parametrik, yaitu Kolmogorov Smirnov test (K-S test). Dari hasil penelitian nilai signifikansi sebesar 0,122. Karena nilai signifikansi lebih besar dari 0,05. Maka dapat disimpulkan data berdistribusi normal.

Tabel 2. Uji Multikolinearitas

Runs Test

\begin{tabular}{ll}
\hline & $\begin{array}{l}\text { Unstandardized } \\
\text { Residual }\end{array}$ \\
\hline Test Value $^{\mathrm{a}}$ & -.37786 \\
Cases < Test Value & 20 \\
Cases >= Test Value & 20 \\
Total Cases & 40 \\
Number of Runs & 22 \\
Z & .160 \\
Asymp. Sig. (2-tailed) & .873 \\
\hline
\end{tabular}

Sumber: Data yang diolah

Berdasarkan hasil uji multikolinearitas menunjukkan bahwa bahwa data hasil penelitian ini tidak terjadi multikolinieritas, yang berarti asumsi multikolinieritas ditolak dan model regresi memenuhi asumsi klasik untuk hal tersebut. 
Tabel 3. Hasil Uji Heteroskedastisitas

\begin{tabular}{lccc}
\hline \multicolumn{1}{c}{ Variabel Independen } & P-value & Sig. & Keterangan \\
\hline Kesadaran Pajak & 0,730 & $>0,05$ & Bebas Heteroskedastisitas \\
$\begin{array}{l}\text { Sistem Administrasi Pajak } \\
\text { Modern }\end{array}$ & 0,987 & $>0,05$ & Bebas Heteroskedastisitas \\
Sanksi Pajak & 0,828 & $>0,05$ & Bebas Heteroskedastisitas \\
\hline
\end{tabular}

Sumber: Data yang diolah

Berdasarkan hasil uji heteroskedastisitas menunjukkan bahwa nilai $\mathrm{P}$ value variabel independen kesadaran pajak, sistem administrasi pajak modern, dan sanksi pajak lebih besar dari 0,05, dapat disimpulkan bahwa tidak ada gejala heteroskesdastisitas dalam penelitian ini.

Tabel 4. Hasil Uji Autokorelasi

\begin{tabular}{ll} 
Runs Test & \\
& $\begin{array}{l}\text { Unstandardized } \\
\text { Residual }\end{array}$ \\
\hline Test Value ${ }^{\mathrm{a}}$ & -.37786 \\
Cases $<$ Test Value & 20 \\
Cases $>=$ Test Value & 20 \\
Total Cases & 40 \\
Number of Runs & 22 \\
Z & .160 \\
Asymp. Sig. (2-tailed) & .873 \\
\hline
\end{tabular}

Berdasarkan hasil uji autokorelasi nilai Asymp.Sig.(2-tailed) sebesar 0,873, maka dapat disimpulkan tidak terjadi autokorelasi, karena nilai Asymp.Sig. (2-tailed) > 0,05.

Tabel 5. Hasil Uji Regresi Linear Berganda

\begin{tabular}{clll}
\hline & $\begin{array}{l}\text { Unstandardized } \\
\text { Coefficients }\end{array}$ & Standardized \\
B & 2,903 & 2,689 & $\begin{array}{l}\text { Coefficients } \\
\text { Beta }\end{array}$ \\
\hline (Constant &, 777 &, 121 & \\
Kesadara &, 264 &, 168 &, 719 \\
$\mathrm{n}$ &,- 163 &, 166 &, 334 \\
SAPM & &,- 208 \\
Sanksi & & & \\
Pajak & & & \\
\hline
\end{tabular}

Sumber : Data yang diolah

Berdasarkan hasil pengujian analisis regresilinier berganda, maka didapat persamaan regresinya sebagai berikut :

$\mathrm{Y}=2,903+0,777 \mathrm{X} 1+0,264 \mathrm{X} 2-0,153 \mathrm{X} 3$

Keterangan:

Y : Kepatuhan Wajib Pajak

$\mathrm{X} 1$ : Kesadaran Pajak

X2 : Sistem Administrasi Pajak Modern 
X3 : Sanksi Pajak

Hasil analisis data diperoleh nilai konstanta (a) sebesar 2,903, koefisien variabel X1 (b1) sebesar 0,777, koefisien variabel X2 (b2) sebesar 0,264, dan koefisien variabel X3 (b3) sebesar -0,163. Hasil analisis data diperoleh persamaan regresinya adalah $\mathrm{Y}=2,903-0,777 \mathrm{X} 1+0,264 \mathrm{X} 2-0,163 \mathrm{X} 3$, dari persamaan tersebut terlihat bahwa koefisien X1 memiliki tanda positif (+). Tanda positif, yaitu 0,777, artinya setiap kesadaran pajak naik sebesar $1 \%$ akan diikuti kenaikan kepatuhan wajib pajak sebesar 0,777 dengan asumsi nilai koefisien variabel independen dianggap tetap atau sama dengan nol. Koefisien X2 memiliki tanda positif (+) yaitu 0,264, artinya setiap sistem administrasi pajak modern naik sebesar $1 \%$ akan diikuti kepatuhan wajib pajak sebesar 0,264 dengan asumsi nilai koefisien variabel independen lainnya dianggap tetap atau sama dengan nol. Koefisien X3 memiliki tanda negatif (-) yaitu -0,163, artinya setiap sanksi pajak naik sebesar $1 \%$ akan diikuti penurunan kepatuhan wajib pajak sebesar 0,163 dengan asumsi nilai koefisien variabel independen lainnya dianggap tetap atau sama dengan nol.

Tabel 6. Hasil Uji F

\begin{tabular}{lllll}
\hline $\begin{array}{l}\text { F } \\
\text { hitung }\end{array}$ & $\begin{array}{l}\text { F } \\
\text { tabel }\end{array}$ & Sig. & Standard & Keterangan \\
\hline 14,596 & $>2,87$ & 0,000 & $<0,05$ & $\begin{array}{l}\text { Model layak } \\
\text { digunakan }\end{array}$ \\
\hline
\end{tabular}

Sumber : Data yang diolah

Berdasarkan hasil perhitungan tersebut diperoleh $\mathrm{F}$ hitung sebesar 14,596. Ternyata besarnya Fhitung terletak didaerah penerimaan Ha yaitu $F$ hitung $>\mathrm{F}$ tabel $(14,596>2,87)$ dan nilai signifikansi sebesar 0,000 yang artinya lebih kecil dari $0,05(0,000<0,05)$. Jadi dapat disimpulkan bahwa secara bersama-sama atau simultan variabel independen meliputi kesadaran pajak, sistem administrasi pajak dan sanksi pajak berpengaruh terhadap variabel dependen yaitu kepatuhan wajib pajak.

Tabel 7. Hasil Uji t

\begin{tabular}{ccrccc}
\hline Hipotesis & t hitung & t table & Sig. & Standard & Keterangan \\
\hline H1 & 6,411 & $>2,02809$ & 0,000 & $<0,05$ & diterima \\
H2 & 1,576 & $>2,02809$ & 0,124 & $<0,05$ & ditolak \\
H3 & $-0,981$ & $>2,02809$ & 0,333 & $<0,05$ & ditolak \\
\hline
\end{tabular}

Sumber : Data yang diolah

Pengaruh kesadaran pajak terhadap kepatuhan wajib pajak

Hasil nilai t hitung $>\mathrm{t}$ tabel $(6,411>2,02809)$ dan signifikansi $<0,05(0,000<0,05)$, maka H0 ditolak (Ha diterima). Jadi dapat disimpulkan bahwa kesadaran berpengaruh secara signifikan terhadap kepatuhan wajib pajak.

\section{Pengaruh sistem administrasi pajak modern terhadap kepatuhan wajib pajak}

Hasil nilai t hitung > t tabel $(1,576>2,02809)$ dan signifikansi < 0,05 $(0,124>0,05)$, maka H0 ditolak (Ha diterima). Jadi dapat disimpulkan bahwa sistem administrasi pajak modern tidak berpengaruh secara signifikan terhadap kepatuhan wajib pajak.

\section{Pengaruh sanksi pajak terhadap kepatuhan wajib pajak}

Hasil nilai $-\mathrm{t}$ tabel $\leq \mathrm{t}$ hitung $\leq \mathrm{t}$ tabel $(-2,02809 \leq-0,981 \leq 2,02809)$ dan signifikansi $>0,05(0,366>0,05)$, maka H0 diterima (Ha ditolak). Jadi dapat disimpulkan bahwa sanksi pajak tidak berpengaruh secara signifikan terhadap kepatuhan wajib pajak.

Tabel 8. Koefisien Determinasi

\begin{tabular}{ll}
\hline Model & Adjusted $R$ Square \\
\hline 1 & 0,511 \\
\hline
\end{tabular}

Sumber : Data yang diolah

Berdasarkan data diatas besarnya nilai adjusted $\mathrm{R}$ square sebesar 0,511 atau $51,1 \%$. Hal ini berarti variabel independen yaitu kesadaran pajak, sistem administrasi pajak modern dan sanksi pajak mampu menjelaskan variabel dependen kepatuhan wajib pajak sebesar 51,1\%, sedangkan 48,9\% dijelaskan oleh variabel lainnya 


\section{KESIMPULAN}

Penelitian ini bertujuan untuk mengetahui kesadaran pajak, sistem administrasi pajak modern dan sanksi pajak terhadap kepatuhan wajib pajak UMKM di Surakarta. Jenis penelitian ini adalah penelitian kuantitatif. Sampel dalam penelitian ini adalah 40 responden. Metode pengambilan sampel dengan metode purposive sampling. Berdasarkan hasil pengujian kelayakan model (uji F) menunjukkan bahwa variabel independen (kesadaran pajak, sistem administrasi pajak modern dan sanksi pajak) berpengaruh terhadap variabel dependen (kepatuhan wajib pajak). Berdasarkan hasil pengujian hipotesis (uji t) menunjukkan bahwa variabel kesadaran pajak berpengaruh terhadap kepatuhan wajib pajak, sedangkan variabel sistem administrasi pajak modern dan sanksi pajak tidak berpengaruh terhadap kepatuhan wajib pajak.

\section{REFERENSI}

Abdullah, Syukriy; Arfan, Muhammad dan Mahfud. (2016). Pengaruh Pemahaman Peraturan Perpajakan, Kesadaran Membayar Pajak Dan Kualitas Pelayanan Perpajakan Terhadap Kepatuhan Wajib Pajak Badan (Studi Empiris Pada Koperasi Di Kota Banda Aceh). Jurnal Magister Akuntansi Pascasarjana Universitas Syiah Kuala Banda Aceh.

Anggraini, Romandana. (2012). Pengaruh Pengetahuan Pajak, Persepsi Tentang Petugas Pajak dan Sistem Administrasi Pajak Terhadap Tingkat Kepatuhan Wajib Pajak Orang Pribadi.

Hidayati, Sri. (2013). Pengaruh Pemahaman Self Assesment System dan Pelayanan Perpajakan Modern Terhadap Kepatuhan Wajib Pajak Dalam Memenuhi Kewajiban Perpajakan. Universitas Islam Batik Surakarta.

Jatmiko, A. (2006). Pengaruh Sikap Wajib Pajak Pada Pelaksanaan Sanksi Denda, Pelayanan Fiskus dan Kesadaran Perpajakan Terhadap Kepatuhan Wajib Pajak. Universitas Dipenegoro.

K Sarunan, Widya. (2015). Pengaruh Modernisasi Sistem Administrasi Perpajakan Terhadap Kepatuhan Wajib Pajak Orang Pribadi dan Wajib Pajak Badan Pada Kantor Pelayanan Pajak Pratama Manado. Universitas Sam Ratulangi Manado.

Mardiasmo. (2011). Perpajakan Edisi Revisi. Yogyakarta: Penerbit Andi.

Maria, Delli. (2013). Pengaruh Moderenisasi Sistem Administrasi Pepajakan Terhadap Tingkat Kepatuhan Pengusaha Kena Pajak di Kantor Pelayanan Pajak (KPP) Pratama Bandar Lampung. Jurnal Bisnis Darmaja Informasi dan Bisnis Istitute Darmaja.

Munari. (2005). Pengaruh Faktor Tax Payer Terhadap Keberhasilan Penerimaan Pajak Penghasilan (Studi Kasus KPP Batu Malang). Jurnal Eksekutif Vol. 2, No. 2.

Nugroho, A. (2006). Memahami Perdagangan Modern di Dunia Maya. Informatika Bandung.

Nurpratiwi, A. (2014). Analisis Persepsi Wajib Pajak Pemilik UMKM Terhadap Penetapan Kebijakan Penghasilan Final Sesuai Peraturan Pemerintah No. 46 Tahun 2013. Universitas Brawijaya.

Olaoye Olatunji, Clement dan Rafiat Ayeni-Agbaje. (2017). Tax Information, Administtration and Knowledge on Tax Payers's Compliance of Bllock Moulding Firms in Ekiti State. Departement of Accounting, Faculty of Management Sciences, Ekiti State University.

Prof, Dr, Rochmat Soemitro, SH. (2009). Perpajakan. Yogyakarta: Penerbit Andi.

Puspitasari, Lidya. (2015). Pengaruh Kesadaran Wajib Pajak, Tingkat Pemahaman Wajib Pajak, Pelayanan Fiskus dan Sanksi Pajak Terhadap Kepatuhan Wajib Pajak. Universitas Riau. 
Rafiat Ayeni-Agbaje, Abiodun, O. (t.thn.). Tax Information, Administration and Knowledge on Tax Payers' Compliance of Block Moulding Firms in Ekiti State. $d$.

Saraswati, Erlita. (2014). Pengaruh Pemahaman Self Assesment System, Pelayanan Perpajakan Modern Dan Sanksi Pajak Terhadap Kepatuhan Wajib Pajak UKM Di Sukoharjo. Universitas Islam Batik Surakarta.

Setyabudi, M. (2017). Pengaruh Sosialisasi Perpajakan, Pengetahuan Perpajakan, Sanksi Pajak dan PPh Final (Implementasi PP Nomor 46 Tahun 2013) Terhadap Kepatuhan Wajib Pajak Orang Pribadi. Universitas Muhammadiyah Surakarta.

Sriarti, Rara. (2000). Studi Tentang Sistem Administrasi Perpajakan dan Kesadaran Masyarakat dalam Membayar PBB di Kelurahan Bandarharjo Kecamatan Semarang Utara. Universitas Dipenegoro.

Suparman. (2007). Sistem Administrasi Perpajakan Modern.

Suyatmin. (2004). Pengaruh Sikap Wajib Pajak Terhadap Kepatuhan Wajib Pajak Dalam Pembayaran Pajak Bumi dab Bangunan Surakarta. Tesis Progam Pasca Sarjana Magister Sains Akuntansi.

Tiraada, Tryana A.M. (2013). Kesadaran Perpajakan, Sanksi Pajak, Sikap Fiskus Terhadap Kepatuhan WPOP di Kabupaten Minahasa Selatan. EMBA Vol. 1 No. 3 September.

Widayati dan Nurlis. (2010). Faktor-Faktor yang Mempengaruhi Kemauan Untuk Membayar Pajak Wajib Pajak Orang Pribadi Yang Melakukan Pekerjaan Bebas. Jurnal SNA XIII. 
